\title{
El análisis táctico en el tenis: desde sus orígenes a la actualidad
}

\author{
Rafael Martínez \\ Universidad de Valencia, Valencia, España
}

\author{
Palabras clave: Análisis \\ táctico, análisis notacional, \\ estrategia \\ Recibido: 14 Diciembre 2017 \\ Aceptado: 27 Febrero 2018 \\ Autor correspondiente: \\ Rafael Martínez \\ Universidad de Valencia, \\ Valencia, España. \\ Correo electrónico: \\ rafael.martínez-gallego@uv.es
}

\section{INTRODUCCIÓN}

El análisis táctico está relacionado con los aspectos estratégicos y tácticos del deporte. La estrategia puede ser definida como el plan establecido previo a la competición, que busca maximizar las fortalezas y reducir las debilidades del jugador, a la vez que minimiza las fortalezas del contrario y aprovecha sus debilidades (O'Donoghue, 2010). Por otro lado, la táctica se asocia con la toma de decisiones de los jugadores durante el juego, basadas en las opciones disponibles y los riesgos y oportunidades asociadas a cada una de ellas (Fuller y Alderson, 1990).

De forma tradicional este análisis se ha realizado de una forma muy poco sistematizada, basada únicamente en la observación directa del entrenador durante los partidos o entrenamientos. Esta forma de analizar la táctica, tal y como indican Murray et al. (2007), conlleva una serie de problemas relacionados con la capacidad de percepción, la memoria y la interpretación de la observación de los entrenadores, que hacen que la información que llega al tenista esté sesgada e interpretada de forma totalmente subjetiva. Por tanto, parece evidente la necesidad de utilizar métodos de observación y análisis, que permitan la obtención de datos objetivos en los cuales se pueda basar la información recibida por el entrenador y posteriormente por el tenista.

\section{EL ANÁLISIS NOTACIONAL}

El análisis notacional permite registrar de forma fiable aquellos indicadores que resulten de interés para evaluar el rendimiento táctico de los jugadores, de modo que la información obtenida por el entrenador y el deportista será mucho más precisa y objetiva (Martínez-Gallego, 2015).

Como se podrá ver a continuación, el avance tecnológico y la incorporación de los ordenadores personales al análisis notacional han marcado de forma significativa su desarrollo y evolución, de ahí que pueda distinguirse entre dos tipos de análisis: el análisis notacional manual y el análisis notacional computerizado.

\section{El análisis notacional manual}

Ya en la época de los egipcios, se hacía uso de este tipo de análisis donde, a través de símbolos y jeroglíficos se representaban patrones de danza y movimientos (Over y O'Donoghue, 2008). Posteriormente, fue precisamente el ámbito de la danza el que parece que sirvió como base para el desarrollo de un sistema de notación general de movimiento. De hecho, el primer sistema para analizar y registrar el movimiento humano fue el Labanotation, creado por Rudolph Laban (Laban, 1975). Por lo que respecta al tenis, el primer sistema de análisis notacional manual publicado fue el llevado a cabo por Downey (1973). Este sistema permitía registrar los tipos de golpes realizados, la posición en la pista, el resultado del golpe y el tipo de efecto utilizado en cada golpe. Debido a su complejidad, tanto para registrar la información como para analizarla, este sistema se llevó muy poco a la práctica, aunque sí fue importante para posteriores investigaciones que se basaron en sus ideas. 


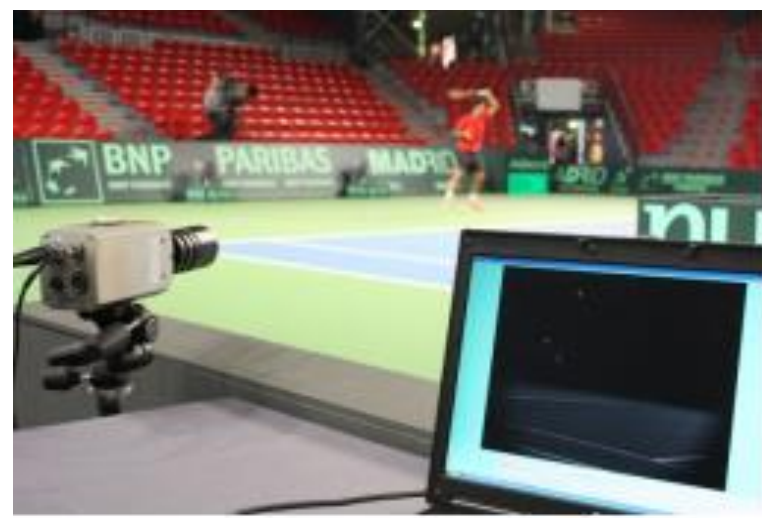

Desde entonces, se ha continuado haciendo uso del análisis notacional manual, utilizando sistemas de registro más simples y adecuados a las demandas y posibilidades de los entrenadores. De hecho, a pesar de la aparición de nuevas tecnologías, todavía es frecuente observar a entrenadores realizando anotaciones manuales durante el desarrollo de los partidos.

\section{El análisis notacional computerizado}

El desarrollo de la informática y el avance de las tecnologías en las últimas décadas, ha supuesto una revolución en el concepto del análisis notacional, permitiendo un registro de la información más preciso y sencillo, facilitando la creación de bases de datos, y dotando de herramientas que hacen que la representación de los datos sea más estética, agradable e intuitiva, y por tanto, más fácil de entender para entrenadores y deportistas (Murray et al., 2007).

Actualmente existen gran cantidad de dispositivos y programas informáticos que se están empleando cada vez más para analizar el rendimiento táctico de los deportistas (Barris y Button, 2008). De la misma forma, la cantidad de programas específicos sobre análisis notacional en el deporte es cada vez mayor. Los programas informáticos que nos ayudan a llevar a cabo este tipo de análisis pueden ser clasificados en dos grandes categorías: "tagging systems" o sistemas de etiquetas, $y$ "tracking systems" o sistemas de rastreo.

Los sistemas de etiquetas, generalmente integran un reproductor de vídeo junto con una interface de botones que pueden ser definidos y etiquetados por el analista. Los eventos introducidos a través de los botones son sincronizados con el vídeo y almacenados en un archivo de datos, de forma que posteriormente se puedan visualizar los eventos deseados y exportar la información a bases de datos para llevar a cabo análisis estadísticos. La flexibilidad de este tipo de programas hace que se puedan crear un número ilimitado de plantillas de análisis que permitan analizar cualquier aspecto del juego. Algunos programas de este tipo que se pueden encontrar en el mercado son: Dartfish (versión TeamPro), Focus o Longomatch.

Los sistemas de rastreo son sistemas más complejos utilizados normalmente por jugadores o en eventos profesionales. Estos programas, a través de las imágenes capturadas por varias cámaras crean una visión en dos o tres dimensiones. A partir de las imágenes obtenidas, el programa, de forma automática o semiautomática, detecta la posición de los jugadores y/o la pelota en cada instante de tiempo, y a partir de ahí se calculan distintas variables cinemáticas que podrán relacionarse con aspectos tácticos y fisiológicos. Algunos ejemplos de programas comerciales de rastreo son Hawk-eye, Amisco o Prozone.

\section{Estudios de análisis táctico en la actualidad}

Finalmente, a modo de ejemplo, vamos a citar algunos de los estudios más recientes relacionados con el análisis táctico, en los que se ha hecho uso de algunas de las herramientas descritas anteriormente, y que pensamos que pueden resultar de interés por su aplicación práctica al entrenamiento.

El primer trabajo al que vamos a hacer referencia es el llevado a cabo por Reid, Morgan, y Whiteside (2016), donde se analizaron las diferencias entre hombres y mujeres en el Open de Australia, en cuanto a dinámicas de golpes y movimiento. Los resultados obtenidos fueron los siguientes:

- El servicio fue el golpe donde aparecieron mayores diferencias, siendo los hombres los que sacaron más rápido, lograron más saques directos y errores forzados en el resto, y ganaron un mayor porcentaje de puntos al servicio.

- En cuanto al resto, las mujeres golpearon más cerca de la red, a menor altura y más plano que los hombres.

- La frecuencia de los golpes de fondo fue similar para ambos sexos, aunque los hombres golpearon a una mayor velocidad, más plano y una mayor cantidad de golpes dentro de la pista.

- No aparecieron diferencias entre hombres y mujeres en cuanto a la distancia recorrida por punto, aunque los hombres mostraron velocidades medias de desplazamiento mayores.

Posteriormente, Kovalchik y Reid (2017) compararon estadísticas de juego y demandas físicas entre jugadores profesionales y Juniors, obteniendo las siguientes conclusiones:

- Los jugadores profesionales obtuvieron una mayor ventaja con el servicio.

- Los jugadores junior consiguieron ganar un mayor porcentaje de puntos de break.

- De forma general, los jugadores profesionales lograron más potencia y precisión en sus golpes, siendo especialmente evidente en el servicio.

- Los jugadores junior sacaron el doble de veces al centro de la pista que los profesionales. 


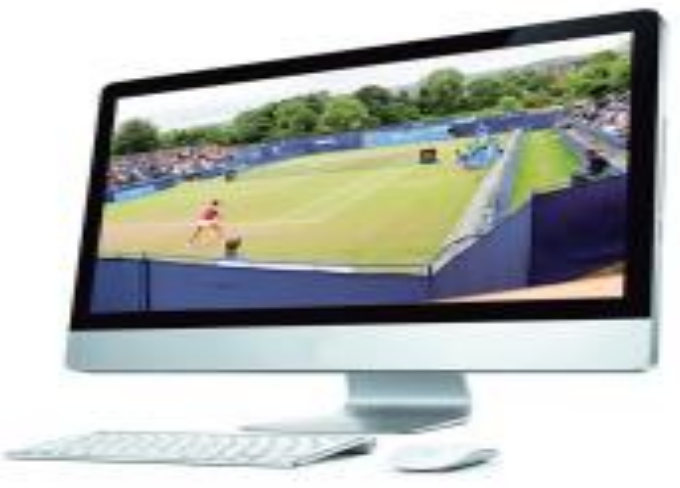

- En hombres, la carga física de los jugadores profesionales durante los partidos fue el doble que la de los jugadores junior, mientras que en mujeres fueron las jugadoras junior las que doblaron la carga física en comparación a las jugadoras profesionales.

Más recientemente, Martínez-Gallego et al. (2018) realizaron un estudio con jugadores profesionales, donde analizaron por un lado, las diferencias existentes entre los ganadores y perdedores de los puntos en cuanto al volumen e intensidad de sus desplazamientos, en función de su posición en la pista, y por otro, las diferencias entre los ganadores y perdedores de los juegos en cuanto a golpes ganadores, errores no forzados y efectividad, en función de su posición en la pista. Las principales conclusiones que se extrajeron en este trabajo fueron:

- Los ganadores de los puntos usaron estrategias más ofensivas, estando más tiempo en zonas ofensivas y forzando a los rivales a recorrer más distancia y a una mayor velocidad.

- Cuando los perdedores de los puntos ocuparon posiciones ofensivas, no aprovecharon esa ventaja posicional, ya que estaban siendo dominados por el rival obligándoles a desplazarse a velocidades altas.

- Los ganadores de los juegos consiguieron un mayor número de golpes ganadores y cometieron menos errores, siendo más eficientes que los perdedores.

- En zonas defensivas no hubo diferencias en cuanto al número de golpes ganadores, sin embargo, los ganadores de los juegos cometieron menos errores no forzados.

\section{REFERENCIAS}

Barris, S., \& Button, C. (2008). A review of vision-based motion analysis in sport. Sports Medicine, 38(12), 1025-1043. https://doi.org/10.2165/00007256-200838120-00006
Fuller, N., \& Alderson, G. J. K. (1990). The development of match analysis in game sports. In Match Analysis in Sport: A state of the art review. Leeds: National Coaching Foundation.

Kovalchik, S. A., \& Reid, M. (2017). Comparing Matchplay Characteristics and Physical Demands of Junior and Professional Tennis Athletes in the Era of Big Data. Journal of Sports Science \& Medicine, 16(4), 489. Laban, R. (1975). Laban's principles of Dance and Music Notation. London: McDonald \& Evans Ltd.

Martínez-Gallego, R. (2015). El análisis de la táctica en el tenis. E-Coach - Revista Electrónica Del Técnico de Tenis, 8(24), 4-9.

Martínez-Gallego, R., Guzmán, J. F., Crespo, M., Ramón-Llin, J., \& Vukovi, G. (2018). Technical, tactical and movement analysis of men's professional tennis on hard courts. The Journal of Sports Medicine and Physical Fitness, (In press). https://doi.org/10.23736/S0022-4707.17.07916-6

Murray, S., Hughes, M. T., White, C., \& Locke, D. (2007). Analysis of performance. In M. Hughes (Ed.), Basics of Performance Analysis (pp. 21-31). Cardiff: Centre for Performance Analysis, UWIC.

O'Donoghue, P. (2010). Research methods for sports performance analysis. London: Routledge. https://doi.org/10.1080/24748668.2010.11868503 https://doi.org/10.1080/24748668.2010.11868495 https://doi.org/10.1080/24748668.2010.11868514

Over, S., \& O'Donoghue, P. (2008). What's the point tennis analysis and why. Coaching \& Sport Science Review, 15(45), 19-21.

Reid, M., Morgan, S., \& Whiteside, D. (2016). Matchplay characteristics of Grand Slam tennis: implications for training and conditioning. Journal of Sports Sciences, 34(19), 1791- 1798. https://doi.org/10.1080/02640414.2016.1139161

\section{CONTENIDO ITF ACADEMY RECOMENDADO (HAZ CLICK ABAJO)}

\section{TTF Academy}

Derechos de Autor (c) 2018 Rafael Martíne

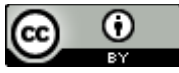

Este texto está protegido por una licencia CreativeCommons 4.0.

Usted es libre para Compartir -copiar y redistribuir el material en cualquier medio o formato- y Adaptar el documento - remezclar, transformar y crear a partir del material- para cualquier propósito, incluso para fines comerciales, siempre que cumpla la condición de:

Atribución: Usted debe dar crédito a la obra original de manera adecuada, proporcionar un enlace a la licencia, e indicar si se han realizado cambios. Puede hacerlo en cualquier forma razonable, pero no de forma tal que sugiera que tiene el apoyo del licenciante o lo recibe por el uso que hace de la obra. 